\title{
Pathway to a fully sustainable global energy system by 2050
}

\author{
Yvonne Y Deng ${ }^{1, *}$, Sebastian Klaus ${ }^{1}$, Stijn Cornelissen ${ }^{2}$, Kees van der Leun ${ }^{1}$, Kornelis Blok ${ }^{1}$ \\ ${ }^{1}$ Ecofys, London, United Kingdom, \\ ${ }^{2}$ Ecofys, Nuremberg, Germany, \\ ${ }^{3}$ Ecofys, Utrecht Netherlands \\ ${ }^{4}$ ZinInZin, Utrecht, Netherlands \\ *Corresponding author. Tel: +44 207423 0984, Fax: +44 207423 0971, E-mail: y.deng@ecofys.com
}

\begin{abstract}
We present a possible pathway to a global, sustainable energy system by 2050. This new energy scenario follows a comprehensive examination to all aspects of energy use across the entire world and the possible means of supplying this energy from the sustainable sources we have available to us. It does so, from the perspective of actual, physical activities that require energy: our industrial processes, our cars, our buildings.
\end{abstract}

For each of these activities, the scenario asks the questions:

- What is the minimum amount of energy required to deliver these functions?

- How can we supply this energy in a sustainable way?

The key aspects of this new Energy Scenario are:

- It is an ambitious, but feasible pathway for all sectors; we can build an energy system by 2050 which sources $95 \%$ of its energy from sustainable sources.

- This energy system will use only a small fraction of each of the sustainable energy sources, making this a robust scenario.

- We can progress towards a world that still sustains comfortable lifestyles, despite consumption patterns, demonstrating a more efficient use of energy and other resources, particularly in developed countries.

- Energy efficiency is the key requisite to meeting our future energy needs from sustainable sources. Total energy demand in 2050 is lower than in 2000, despite the growth of population and energy services.

- Electricity is the energy carrier most readily available from sustainable energy sources and therefore, electrification is key.

- All bioenergy required, (primarily for residual fuel and heat demands) can be sourced sustainably, provided the appropriate management practices and policies are in place.

- The scenario's energy system will have large cost advantages over a business-as-usual system because the initial investments will be more than offset by savings made on energy costs, in later years.

The scenario is based on a comprehensive energy model, developed by Ecofys, to establish a scenario for future energy demand and supply worldwide. Unlike many world models, it is based on physical activity indicators and takes a comprehensive look at all aspects of energy demand and supply across all sectors.

The work pays particular attention to the implementation speed of sustainable energy technologies and assesses energy at the detailed carrier and sub-sector level.

It also contains a comprehensive assessment of biomass as a sustainable energy source, with a multitude of different source options and conversion technologies, subject to stringent sustainability criteria.

Keywords: Sustainability, Renewable energy, Energy efficiency, Scenario, Global

\section{Introduction}

The last 200 years have witnessed a substantial increase in energy use by societies worldwide. In recent decades, it has become clear that the way this energy is supplied is unsustainable and now both, short- and long-term energy security, are at the top of the political and societal agenda.

Evidence suggests that we should be able to meet our energy demand from renewable sources, given their abundance: Worldwide energy use, in units of final energy (after conversion from 
primary fuels), was 310 EJ in 2007 ( 500 EJ in primary energy terms) [1] whereas technical potentials range from 100s to 1000s of EJ/a (see Fig. 3).

In an attempt to reconcile these figures, the energy scenario provides a comprehensive view of the energy system. It incorporates and examines all energy uses; all quantities, locations, carrier forms (e.g. electricity or fuel) and all purposes (heat in buildings or heat in industry)

This level of detail is (partially) captured in the various energy scenario models that are currently used to predict the most likely energy future for the world and the possible alternative scenarios. However, because cost-optimisation is often the driving algorithm, not many of the models have been used to push the share of renewable sources in the energy system to the highest technically possible levels. One of the few studies which has prioritised renewable sources, is the Energy [R]evolution published by Greenpeace. [2] Even this scenario however, falls short of reaching a fully sustainable energy system by mid-century.

The fundamental question that guided this study was:

\section{“Is a fully sustainable global energy system possible by 2050?”}

We find that an (almost) fully sustainable energy supply is technically and economically feasible, given ambitious, yet realistic growth rates of sustainable energy sources. The path to achieving this system deviates significantly from 'business as usual' and the difficult choices that must be made on the way are discussed in this article.

This article is a summary of three full-length publications. The reader is referred to the full publications.[3]-[5]

\section{Methodology}

Energy demand is the product of:

- the volume of the activity requiring the energy (e.g. travel or industrial production), and

- the energy intensity per unit of activity (e.g. energy used per volume of travel).

This energy scenario forecasts future global demand and supply by inherently following the paradigm of Trias Energetica:

1. Reducing energy demand to the minimum required to provide energy services

2. Providing energy by renewable, where possible, local, sources first

3. Providing remaining energy from 'traditional' energy sources as sustainably as possible.

The Trias Energetica approach was translated into this calculation logic:

1. Future energy demand scenario

a. Future demand side activity was based on existing studies or projected from population and GDP growth.

b. Future demand side energy intensity was forecasted assuming fastest possible roll-out of most efficient technologies.

c. The resulting energy demand was aggregated by carrier (electricity, fuel, heat).

2. Future supply scenario

a. The potential for supply of energy was estimated by energy carrier 
b. Demand and supply were balanced in each time period according to the following prioritisation:

i. Renewables from sources other than biomass (electricity and local heat)

ii. Biomass up to the sustainable potential

iii. Traditional sources, such as fossil and nuclear which were used as 'last resort'.

Energy flows have been characterised by carrier type and differentiated into electricity, heat and fuels, consistent with the energy carriers reported in the IEA energy balances, to which this work is calibrated, with 2005 as the base year. [6]

Unless stated otherwise, all energy in this publication is final energy.

\subsection{Sector definitions}

There are many different ways of analysing energy demand. We have chosen to distinguish between energy demand in industry, buildings and transport. (These sectors are congruent with the sectors for which the International Energy Agency (IEA) reports energy statistics, which form the basis of this work.) These three sectors, which cover $\sim 85 \%$ of total energy use, were studied in detail. The remaining sectors, (including agriculture, fishing, mining etc.) are included in this study, but were not examined separately. Non-energy use of energy carriers was excluded from this analysis.

In the Industry sector, we distinguish between ' $A$ ' sectors, for which actual activity measures are available (Iron \& steel, non-ferrous metals, non-metallic minerals, paper \& pulp) and 'B' sectors, for which activity has to be based on proxy indicators, such as value added (Chemical \& petrochemical, food \& tobacco, all others).

\section{Results - Part 1: Demand}

For each of the sectors, we established an activity and energy intensity forecast, to arrive at a final demand projection for the period to 2050.

\subsection{Activity}

Activity forecasts were made as follows:

- Industry: Population and GDP forecasts were coupled with assumptions on the evolution of per capita production of industrial products.

- Buildings: Population and GDP forecasts were coupled with assumptions on the evolution of per capita residential and commercial building areas.

- Transport: Modal shifts, (from road and air to rail transport) are incorporated into an existing BAU transport scenario [7].

The overall evolution of activity is given in Fig. 1.

\subsection{Intensity}

The most significant means of reducing energy demand is the efficient use of energy, i.e. the reduction of energy intensity to a minimum.

We describe our approach to each sector's energy intensity below. 


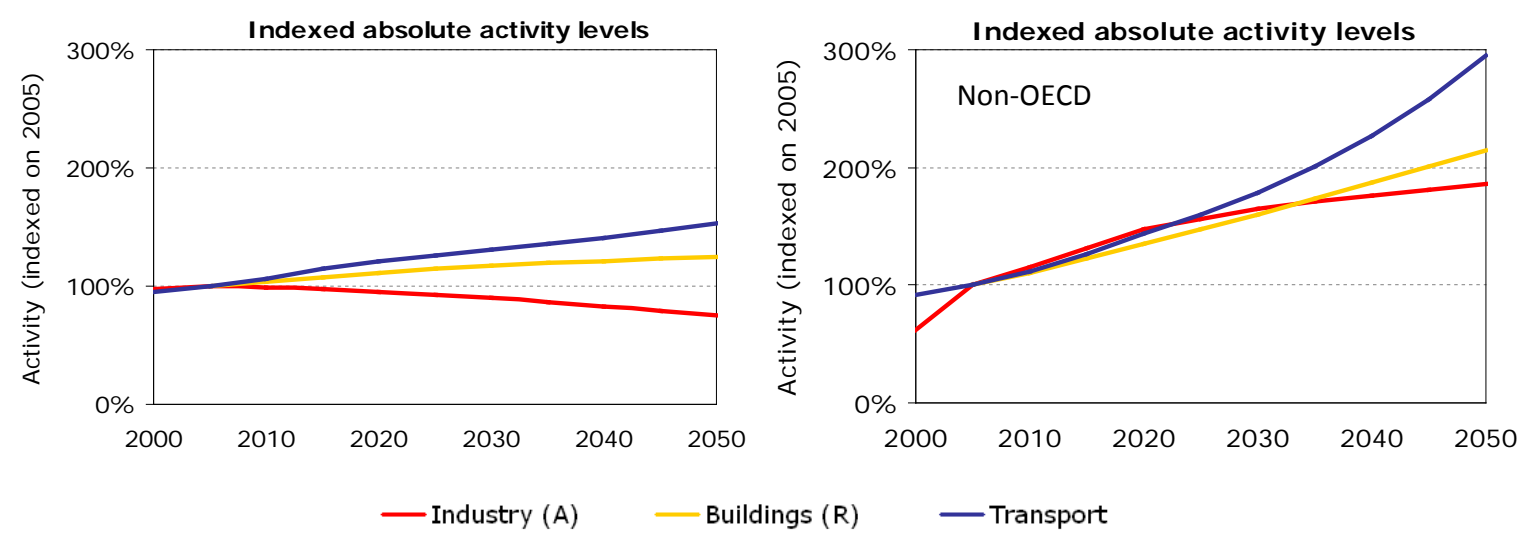

Fig. 1 Activity levels indexed on 2005 in absolute terms. Shown industrial production volumes in the 'A' sectors (Industry), residential floor space (Buildings), and passenger kilometers (Transport).

\subsubsection{Industry}

Future energy intensity is projected based on key marker processes. We adopt a decrease in energy intensity, measured in energy per tonne produced for ' $A$ ' sectors [8]-[11], and in energy per economic value for ' $\mathrm{B}$ ' sectors.

\section{'A' sectors}

The energy intensity evolution was examined in detail for the four ' $A$ ' sectors, yielding, on average, a $\sim 50 \%$ reduction in energy used, per tonne of material produced in 2050 against the 2000 figures. Although the individual technologies vary by sector, all sectors follow these common assumptions:

- Increased use of recovered input materials or alternative routes

o i.e. recycling of steel, paper and aluminium and alternative input materials into the clinker process in cement production

- Ambitious refurbishment of existing plants to meet performance benchmarks

- Stringent requirements for using best available technology (BAT) in all new plants.

- Continuing improvements of BAT over time

\section{'B' sectors}

For the ' $\mathrm{B}$ ' sectors, an annual efficiency improvement of $2 \%$ was adopted, which may be obtained through improved process optimisation, more efficient energy supply, improved efficiency in motor driven systems and lighting and sector-specific measures.

\subsubsection{Buildings}

The following steps are followed to project the future evolution of energy intensity, i.e. the possible future heat and electricity demand per square metre of living or commercial floor space.

\section{Existing buildings stock}

1. All existing buildings will have to be retrofitted by 2050 to ambitious energy efficiency standards. This requires retrofit rates of up to $2.5 \%$ of floor area per year, which is high (compared to current practice), yet feasible.

2. For any given retrofit it is assumed that, on average, $60 \%$ of the heating requirements are abated by insulating walls, roofs and ground floors, replacing old windows with 
highly energy efficient windows and by installing ventilation systems with heat recovery mechanisms.

3. A quarter of the remaining heating and hot water need is met by local solar thermal systems and the rest, by heat pumps.

4. Cooling is provided by local, renewable solutions, where possible.

5. Increased electricity needs per floor area due to increased cooling demand, increased use of appliances (per area) and heat pump powering have been partially offset by increasing efficiency.

\section{New building stock}

1. Increasingly, new buildings will be built to a 'near zero energy use' standard, reaching a penetration of $100 \%$ of new buildings by 2030 .

2. The residual heat demand is met by passive solar (radiation through windows) and internal gains (people, appliances), renewable energy systems in the form of solar thermal installations and heat pumps.

3. This building type only requires electric energy.

4. The near zero-energy concept is applied to warm/hot climates, often returning to traditional building approaches.

5. There is a residual cooling demand in warm/hot climates. Increased electricity needs from increased cooling and appliances, as well as the use of heat pumps, have been estimated and included in this scenario.

\subsubsection{Transport}

The following steps ensure that the scenario employs the most efficient transport modes that have the greatest possible share of renewable energy in the energy supply:

1. Moving to efficient technologies and modes of employment, e.g. trucks with reduced drag, improved air traffic management or reduced fuel needs in hybrid buses.

2. Electrifying the mode as far as possible, e.g. electric cars in urban environments and electric rail systems.

3. Finally, providing the fuel from sustainable biomass, where possible (see next section).

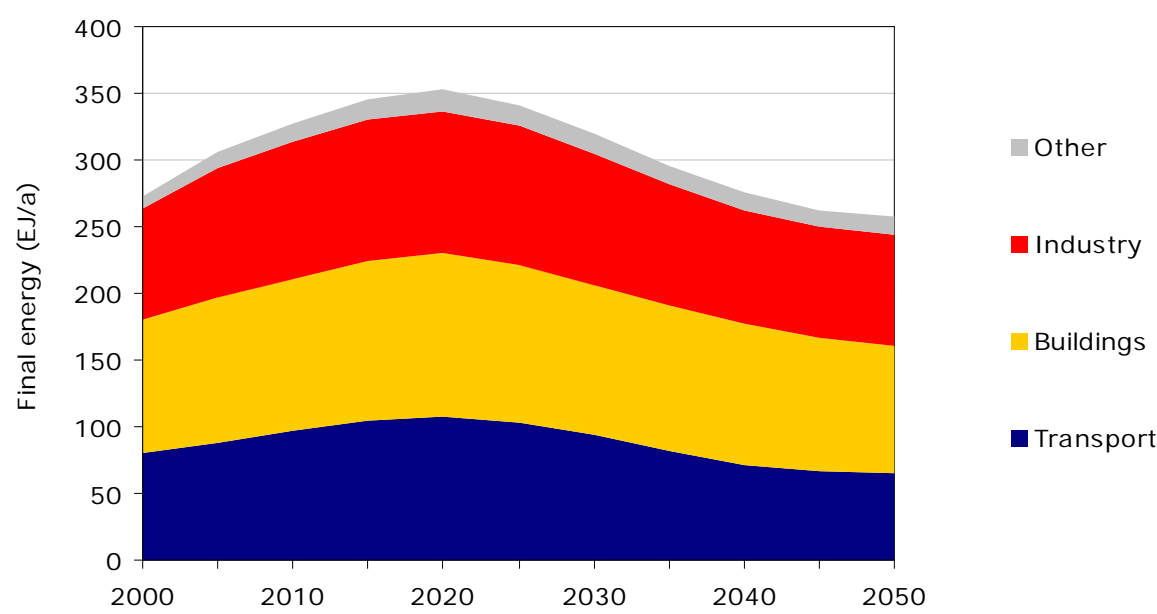

Fig. 2 Global energy demand across all sectors, from 2000 to 2050.

Noteworthy assumptions are:

- A complete shift to plug-in hybrids and/or electric vehicles as the primary technology choice for light-duty vehicles. 
- Long-distance trucks undergoing significant efficiency improvements due to improved material choice, engine technology and aerodynamics, rather than a complete electrification of freight road transport (due to the prohibitive size and weight of batteries required with current technology). Delivery vans covering 'the last mile' are electrified, leading to an electric share estimate of $30 \%$ for trucks.

- A (small) share of shipping fuel gradually being replaced by hydrogen, won from renewable electricity. This has been deemed a feasible option because of the centralised refuelling of ships.

\subsection{Summary}

The activity and intensity assumption detailed above lead to the following overall evolution of energy demand (Fig. 2)

\section{Results - Part 2: Supply}

\subsection{Renewable sources excluding bioenergy}

Once total demand has been established, demand must be matched with energy supply.

This scenario is based on the deployment potential shown in Fig. 3. This is the potential which can be captured at any time, considering technical barriers and ambitious, yet feasible market growth developments. The deployment potential does not necessarily represent the most cost-effective development, i.e. it does not account for market barriers or competition with other sources.

The realisable potential (R.P.) is the fully achievable potential of the resource with a longterm development horizon.

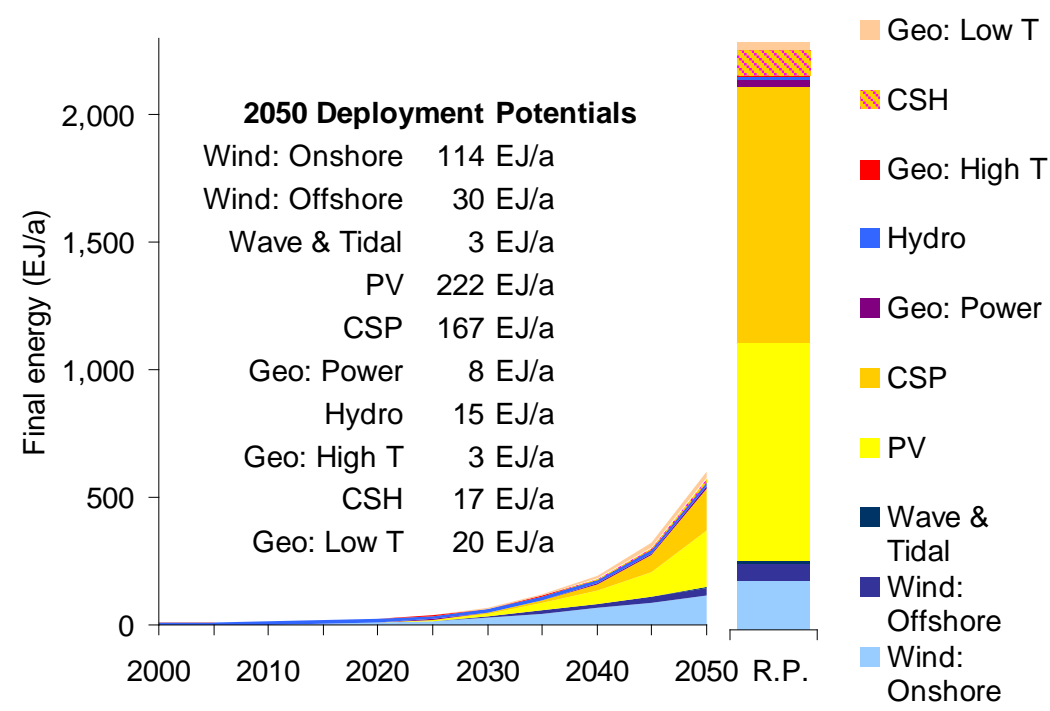

Fig. 3 Global renewable energy potentials (excl. bioenergy), from 2000 to 2050. [5], [12]-[29]

\subsection{Bioenergy}

The scenario incorporates a significant share of sustainable bioenergy supply to meet the remaining demand once other renewable energy options have been employed. The scenario only includes bioenergy supply that is sustainable and leads to high greenhouse gas emission 
savings in comparison to fossil references. The complete approach the scenario takes to bioenergy is discussed in a separate publication. [4]

\subsection{Results of balancing demand and supply}

Following the strict prioritisation of options described in the Methodology section, the overall evolution of energy supply is determined, as shown in Fig. 4.

Stabilising energy demand, driven by strong energy efficiency, coincides with fast renewable energy supply growth in later years, resulting in an energy system that is $95 \%$ sustainably sourced.

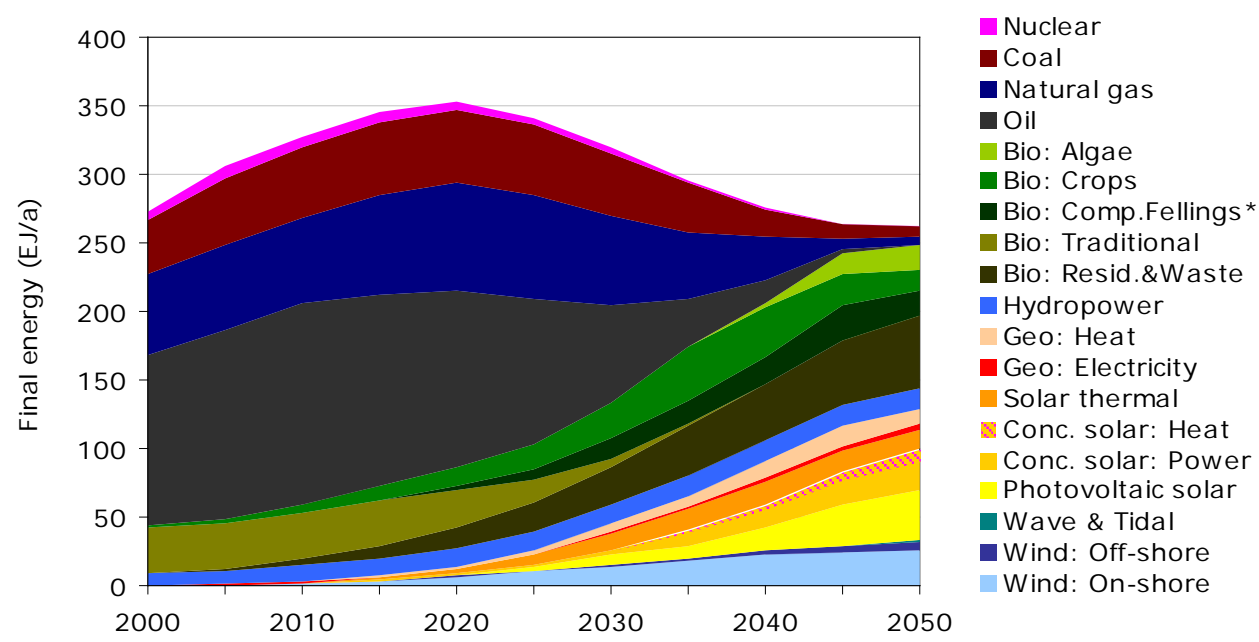

Fig. 4 Global energy supply in the Scenario, split by source. $\left({ }^{*}\right.$ Complementary fellings include the sustainable share of traditional biomass use.)

\section{Discussion}

The energy scenario we have presented combines the most ambitious efficiency drive with a high-growth of renewable source options to reach a fully sustainable global energy system by 2050. Both sides of the equation are important: the transition to a renewable energy system cannot be achieved on the supply side alone.

This energy scenario examines the feasibility of a fully renewable energy future by taking a bottom-up, physical approach to the energy system. It does not necessarily present the most cost-efficient way of achieving this goal. It is however, insightful to estimate the associated investment and savings of this energy system in comparison to a BAU energy system.

This cost study is presented in a separate publication. [5] The key findings are, that upfront investments are estimated at less than 2\% of global GDP and the energy system proposed in this scenario would be significantly cheaper to operate than BAU by 2050 .

\section{References}

[1] International Energy Agency (IEA), World Energy Balances, OECD and nonOECD databases, 2009 Edition

[2] Krewitt et al., Energy [R]evolution 2008-a sustainable world energy perspective, Energy Policy (2009), doi:10.1016/j.enpol.2009.08.42 
[3] Deng et al.,Transition to a fully sustainable, global energy system, 2011, [in preparation]

[4] Cornelissen et al., The role of bioenergy in a fully sustainable, global energy system, 2011, [in preparation]

[5] Klaus et al., Costs and benefits of a fully sustainable, global energy system, 2011, [in preparation]

[6] IEA, World Energy Balances, OECD and nonOECD databases, 2008 Edition

[7] IEA/SMP, Model Documentation and Reference Case Projection for WBCSD's Sustainable Mobility Project (SMP), 2004

[8] N. Martin et al., Emerging Energy-Efficient Industrial Technologies, Lawrence Berkeley National Laboratory, 2000, DC (LBNL-46990).

[9] Kim et al., Energy Policy 30, 2002, p. 827

[10]Worrell et al., World Best Practice Energy Intensity Values for Selected Industrial Sectors, Lawrence Berkeley National Laboratory, LBNL-62806, 2008

[11]IEA, Tracking Industrial Energy Efficiency and CO2 Emissions, 2007

[12]Ecofys, 2008, [internal assessment]

[13] Global Wind Energy Council - GWEC, Global Wind Report 2007, 2007

[14]Hoogwijk et al., Global potential of renewable energy sources: a literature assessment, Ecofys Netherlands, 2008

[15]Leutz et al., Technical offshore wind energy potentials around the globe, European Wind Energy Conference and Exhibition, Copenhagen, Denmark, 2001

[16] Global Status Report, REN21 (Renewable Energy Network for the 21st Century), 2010

[17] China Wind Power Report, ISBN: 978-82-90980-29-9, WWF China, Chinese Renewable Energy Industries Association, 2008

[18]Climate Solutions, WWF, 2006

[19]European Ocean Energy Roadmap, European Ocean Energy Association, 2010

[20]IEA, Implementing Agreement on Ocean Energy Systems, 2009 Annual Report, 2010

[21]EPIA, Solar Generation V, 2008

[22]EPIA, Global Market Outlook for Photovoltaics until 2013, 2009

[23] Hofman et al., The potential of solar electricity to reduce CO2 emissions, Report no. PH4/14 for the Executive Committee of the IEA Greenhouse Gas R\&D Programme, 2002

[24] Li et al., 2007 China Solar PV Report, China Environmental Science Press

[25]DLR, Concentrating Solar Power for the Mediterrenean Region, MED-CSP, 2005

[26] Lund et al, Geothermics 34, 2005, p. 691-727

[27]Bertani, Geothermics 34, 2005, p. 651

[28]Bertani, EGC 2007, Unterhaching, Germany

[29] “The Investor's Guide to Geothermal Energy”, 2008 